\title{
Problems of Molecular Biology teaching for Food Safety and Quality Specialty and reforming idea
}

\author{
Xin Lü \\ College of Food Science and Engineering \\ Northwest A\&F University \\ Yangling, China \\ xinlu@nwsuaf.edu.cn
}

\author{
Xiaoni Zhang* \\ College of Economics and Management \\ Northwest A\&F University \\ Yangling, China \\ kellizhang@163.com, *contributed equally
}

\begin{abstract}
Because the people's living standard is keep improving and food safety accidents occurred frequently in recent years, food quality and safety problem, which is one of the most important research field in food science, is increasingly focused on. The specialty of food quality and safety was established to meet the increasing requirements of professional talents. Molecular biology course is the basic course in food quality and safety specialty syllabus. Based on the introduction of the position, functions and problems of the molecular biology course in food quality and safety specialty, it is primarily suggested that the teaching content should be reasonably set and improved, the teaching method should be changed from chalk-and-talk to heuristic, participatory and constructivism teaching method as well as the exploration experiments should be added and redesigned in the course. Moreover, practical teaching should be supplemented and web-based interaction teaching should be fully used to supplement inadequate credit hours. Through the reforming measures, the molecular biology course can meet the requirement of career development for students majored in food quality and safety and most importantly make students know how to study and construct knowledge by themselves.
\end{abstract}

Keywords-reforming; molecular biology; food safety and qualitye;constructivism

\section{INTRODUCTION}

With the development of society and economy, people pay much attention on food safety and healthy function of food, however, the food safety accidents, such as melamine accident, plasticizer accident and clenbuterol accident, occurred frequently in recent years in China, which make the food quality and safety problem become prominent [1-4]. On the other hand, with the quick development of food industry, food quality and safety problem as well as the resulting hazard increase and become complicated because the influencing factors increase, which has become a critical limitation point in food industry $[5,6]$. In such severe food safety situation, the food quality and safety specialty was firstly established by Northwest A\&F University in 2001, thereafter 117 universities set the food quality and safety specialty [7-9]. Through four years' education, students majored in food quality and safety should grasp the knowledge and skill in food science, biology, nutriology and toxicology as well as the knowledge of law in food quality and safety worldwide. After graduation, students can pursue an occupation of food analytical control, quality management and $R$ \& $D$ in food companies, governmental departments and academic institutions concerned on food quality and safety $[10,11]$.

The courses for food quality and safety specialty include food chemistry, food microbiology, food toxicology, food standards and laws, food process technology, food environmentology, food quality management, food safety control technologies, food analysis and molecular biology, etc. Among these courses, molecular biology is one of the most important courses for students to grasp basic molecular biology knowledge and biological experiments aiming to utilization in food science and technologies [11]. Molecular biology is the branch of biology that deals with the molecular basis of biological activity, in which it chiefly concerns itself with understanding the interactions between the different types of DNA, RNA and protein biosynthesis as well as learning how these interactions are regulated [12,13]. With the development of life science, the molecular biology changes quickly and new knowledge continuously increase. Through studying of molecular biology, students can grasp basic knowledge and experimental skills of molecular biology, know the status and development of molecular biology such as genetic modified food, molecular analytical methods for pathogens and spoiling microorganism, etc.

\section{PROBLEMS IN TEACHING ACTIVITIES}

Though much achievements has been obtained in teaching process of molecular biology, there still exist some problems in molecular biology teaching process practically, which were illustrated as follows.

\section{Limitation of total credit hours}

Because food quality and safety specialty is an engineering specialty, thus the teaching of molecular biology is significantly different with scientific specialty from teaching contents to teaching mode. Firstly scopes and depths of teaching contents are less than corresponding course in scientific specialty. Secondly, students of scientific specialty have more consolidated foundation on biochemisty, genetics, cell biology and other related life sciences than the students of food quality and safety specialty. Actually there are not genetics course and cell biology course for engineering students at all. Thirdly, the course credit hours of molecular biology in food quality and safety specialty is only 33 hours which is also less than 80 hours in scientific 
specialty according to the undergraduate academic program[10]. Therefore, if the teaching contents follow the scientific specialty's, it is inconformity to the teaching law and also can not meet the specialty requirements. The course content, objectives and experiments should be adjusted especially according to the engineering specialty characteristics and less course credit hours.

\section{Limitation of traditional teaching mode}

Similar as other courses, the traditional chalk and talk teaching mode is still the main teaching mode in molecular biology course, in which students are passively receiving knowledge information. In the class, students participate in the course rarely and rapid response from students can not be obtained, let alone explore and construct knowledge by themselves. In fact, how to activating the students' subjective initiative and make students as center are key problems for every teacher.

\section{Contents of textbook lag behind latest molecular biology research}

The development of molecular biology and related scientific field is definitely quick, however, the contents of the molecular biology textbook can not follow the development timely. Thus part of the knowledge will become old-fashioned and even complete wrong if the teacher only read and teach the old teaching material without updating the knowledge and grasping the trend of the molecular research.

\section{Lack of exploration and/or designing experiments}

Molecular biology is a science mainly based on results of experiments thus experiments are important part in molecular biology teaching process. However, current experiments in molecular biology are mainly composed of demonstration experiments while lack of exploring experiments and/or designing experiments. Furthermore, even though demonstration experiments, students rarely connect the scientific knowledge with the experiments and think "why" in the experiments process, contrarily they often only do the experiments according to experiments' guide book. Therefore, it is very important to make students understand the principle of experiments and conduct or design certain exploration and creative experiments for improving creative thinking of students and making students know hot to use scientific knowledge in practice.

\section{reforming idea}

Based on the above analysis of existing problems in molecular biology teaching, some teaching reform suggestions are put forward as follows.

\section{New teaching material should be edited}

Nowadays, Modern Molecular Biology edited by Professor Zhu Yuxian is adopted as teaching material in our college, which is a good scientific teaching material with good illustration and experiments guide [12]. However, it is edited mainly for students in scientific specialty thus it is difficult for students of engineering specialty. Further, it is difficult to introduce all contents of the book in such short credit hours. Therefore it is primarily suggested that the teaching program of molecular biology should be modified to adapt to food quality and engineering specialty. Accordingly the teaching material should be edited to meet the requirements of engineering specialty. For example, the gene expression and its regulation can be shortly introduced compared with detail introduction of DNA, RNA and protein biosynthesis and relationship in the teaching material writing process. Besides, the molecular detection methods for genetic modified food, heavy metal and fungal toxin in food and other related molecular biology theory for food should be introduced, which include southern blot, northern blot and western blot for instance. Secondly, it is suggested that more teaching material, which include molecular biology edited by Robert F.Weaver [13] and Molecular Biology of the Gene edited by James.D. Watson et al.[14] for instance, should be integrated together with the basic teaching material to mutually supplement the teaching contents in the teaching process. Thirdly, it is suggested that bilingual education should be implemented in the teaching activity because most recent life science advancement related to molecular biology is often published in English, which help and guide students track updating knowledge of molecular biology.

\section{Constructivism teaching should be implemented}

Traditional chalk and talk teaching often ignore the response from students and only teacher continuously talk and teach in the whole class hours. Actually courses' teaching process actually include teaching process of teachers and learning process of students, in which students should be the center of the class, tearcher should act as helper and organizer named constructivism teaching[15,16]. Thus good interaction between teachers and students is necessity to guarantee the teaching effects as well as the learning efficiency Further, heuristic teaching is and should be used in the teaching activities, in which teacher firstly give some experiments based on everyday life examples or students known examples in other courses to draw out the question for students thinking and answering according to their existing knowledge thereafter teacher correct and supplement the answer, naturally new concepts and knowledge can be introduced and constructed by students themselves. Secondly, short-time seminar can be hold to discuss recent highlight points in food quality and safety related to molecular biology, in which students was required to prepare the background knowledge, experiments description and problems similar as teacher's preparation of the course. Through above preparation and discussion, students can initiatively explore, think and establish the knowledge internally.

Keeping up with the frontier in molecular biological science, updating teaching content timely

Research on molecular biology is updating quickly, in which both theoretical and experimental advancements are updated quickly. Thus it require teacher keep up with international research frontier and accumulate more knowledge on molecular biology by reading such journals as 
Nature, Science and Cell, through which teacher can update the teaching contents timely. Moreover, teacher should do research on molecular biology to promote the understanding of molecular biology and is naturally prone to bring new knowledge to students in class. For example, author is doing research work on lactic acid bacteria and thus naturally can introduce some new knowledge on detection and identification of microorganism by molecular methods.

\section{Increasing exploration and designing experiment}

Actually molecular biology is a science which was established based on experiments, thus experiments play important role in the teaching process of molecular biology. Through experiments, students can creatively study and apply what they have learned in molecular biology. However, limited by the credit hours and experiments' fund, developing research or exploration experiments is still difficult. On the other hand, less basic molecular experiments skills of students in food safety and quality specialty hinder research or exploration experiments' development. Nevertheless, the teaching effects of research or exploration experiments are best for students to grasp and apply related knowledge, which should be tried in the future though many difficulties still exist.

\section{Enhancing practical ability, increasing practical teaching hours}

Food quality and safety is an engineering specialty thus practical ability is necessity for the students in the specialty. It is suggested that practice should be added to make students know the industrial needs and requirements of government, company and universities through visit and survey, then the actual problems can be brought back which can promote students think what molecular biology can do in solving these actual problems.

\section{Fully utilizing web-based course instruction system}

A web-based instruction system has been established by our university for all graduates and undergraduates, on which teacher can modify teaching program, arrange the course assignments, discuss with students, etc. In other words, teacher can accomplish all teaching activities and communicate with students in real time, which remedy the short credit hours of molecular biology course. Moreover, net-work is a prompt tool to connect teacher and students, which is preferred by modern college students. Thus teacher can extend the teaching course by the web out of the classroom.

\section{CONCLUSIONS}

Since the animal, plant and microorganism are raw materials in food industry, which make molecular biology is increasingly important in the food quality and safety specialty and food science and engineering specialty. However, short credit hours and inappropriate course textbook and other problems existed in teaching progress make us think and give some suggestions to improve the teaching process. For example, the molecular biology textbook for food quality and specialty should be modified and credit hours should be increased. Through these improvements, teaching process might become better and make students know how to study and construct knowledge by themselves

\section{REFERENCES}

[1] Guanghua Qiao , Ting Guo, K.K. Klein. 2012 Melamine and other food safety and health scares in China: Comparing households with and without young children. Food Control, 26(2):378-386

[2] Gui zhiwen, Shen Yipin, Shen Weitao. Outline of food safety accidents in 2011. Food and Life. 2012,1:18-20

[3] Zhou Xubao. Analysis and strategy for food safety accidents in China. Quality and Safety of Agro-Products. 2012,1:69-71

[4] Jiang Liwen; Zhou Hongli; Liu Suchun; Deng Fangming; Xia Yanbin. Thinking of how to establish the specialty of "Food quality and safety". Journal of Food Safety \& Quality. 2011, 2(4):218-222

[5] Caroline Opolski Medeiros, Suzi Barletto Cavalli, Elisabete Salay, Rossana Pacheco C. Proença. Assessment of the methodological strategies adopted by food safety training programmes for food service workers: A systematic review. Food Control. 2011, 22 (8): 1136-1144

[6] Lorna Zach, M. Ellin Doyle, Vicki Bier, Chuck Czuprynski. Systems and governance in food import safety: A U.S. perspective. Food Control. 2012, 27(1): 153-162

[7] Fu Hong-jun Tang Xiao-hong Peng Xiang-lian. Considerations on Training and Curriculum of Food quality and safety speciality. The Food Industry. 2011, 7:110-113

[8] Huang Aixiang, Gong Jiashun, Yuan Wei.Thinking on characteristic establishment of food qualtiy and saftey specialty. Higher Agricultural Education, 2011, 6: 48-50

[9] Shen Xiaofang, Liu Jie, Zhang Hao. Thinking and exploration of teaching mode for food quality and safety. China Education Innovation Herald, 2009,34:172

[10] Liu Jingbo. Suggestions on establishement of teaching guide committee for food quality and safety specialty in the Ministry of Education. Letters for teaching guide committee in Ministry of Education. 2009, 2:4-9

[11] Teaching affairs office of NWSUAF. Undergraduate academic program(2008edition). 2012

[12] Zhu Yuxian, Li Yi, Zhen Xiaofeng. Modern molecular biology 3rd edition. Beijing, Higher Education Press. 2007

[13] Rober F.Weaver. Translated by Zhen Yonglian, Zhang Fuchun, Xu Qijiang, Yue Bingyi. Molecular biology $\left(4^{\text {th }}\right.$ edition $)$. Beijing, Science Press. 2010.

[14] James.D. Watson. Translated by Yang Huan-ming. Molecular biology of the gene( $6^{\text {th }}$ edition).Beijing, Science Press. 2009

[15] Marlies Baeten, Eva Kyndt, Katrien Struyven, Filip Dochy. Using student-centred learning environments to stimulate deep approaches to earning: Factors encouraging or discouraging their effectiveness. Educational Research Review 2010 (5): 243-260

[16] Yucel Gelisli. The effect of student centered instructional approaches on student success. Procedia Social and Behavioral Sciences 2009 (1): 469-473 